\title{
Perubahan Warna Resin Komposit pada Perendaman Larutan Cuka (Asam Asetat) dan Jeruk Nipis (Citrus arantifolia)
}

\author{
Evica F. L. Makasenda \\ Dinar A. Wicaksono \\ Johanna A. Khoman \\ Program Studi Pendidikan Dokter Gigi Fakultas Kedokteran
Universitas Sam Ratulangi Manado
Email: evicamakasenda2@gmail.com
}

\begin{abstract}
In this globalization era, Indonesian people especially in Sulawesi Utara are aware of oral health. Their awareness is related to oral diseases as well as aesthetics. Good aesthetics can be achieved by using several methods inter alia composite resin restoration. However, this composite resin undergoes discoloration in the mouth. To overcome the discoloration of the composite resin, alternative materials like acetic acid and lime that can remove the colored substances adhered on the composite resin are introduced. This study was aimed to determine the discoloration of composite resin immersed in acetic solution and in fresh lime juice. This was a true experimental study with a pretest and posttest group design. This study was conducted in 5 days. Daily observation at the same time was perormed by using spectrophotometer to all samples. Data were processed with Microsoft excel and presented in tables. The results showed that based on the spectrophotometer measurement, the composite resins' color immersed in carbonate solution changed (became brighter) after immersion in acetic solution (from 0.72 to 1.52 ) and in lime juice (from 0.68 to 1.48). Conclusion: The color of discolored composite resins immersed in acetic acid solution and fresh lime juice became brighter.
\end{abstract}

Keywords: composite resin, discoloration, acetic solution, lime.

\begin{abstract}
Abstrak: Pada era globalisasi saat ini, masyarakat Indonesia khususnya di Sulawesi Utara mulai sadar akan kesehatan gigi dan mulut. Kesadaran masyarakat tersebut tidak hanya mengenai penyakit gigi dan mulut, melainkan juga masalah estetik gigi. Estetik yang baik dapat dilakukan dengan banyak cara, salah satunya tindakan penumpatan dengan menggunakan resin komposit. Resin komposit memiliki kecenderungan berubah warna pada saat digunakan di rongga mulut. Perubahan warna menjadi penyebab diperlukannya penggantian bahan tumpatan (resin komposit). Untuk menghemat biaya terdapat alternatif lain seperti asam cuka (asam asetat) dan jeruk nipis yang dapat mengangkat zat-zat warna yang menempel pada resin komposit. Penelitian ini bertujuan untuk mengetahui perubahan warna resin komposit yang direndam dalam larutan cuka dan perasan jeruk nipis. Jenis penelitian ialah eksperimental semu dengan pretest and posttest group design. Penelitian dilakukan selama 5 hari dan dilakukan pengamatan setiap harinya pada jam yang sama dengan menggunakan alat spektrofotometer untuk sampel larutan cuka dan sampel jeruk nipis. Data hasil penelitian diolah menggunakan program komputer microsoft excel dan disajikan dalam bentuk tabel. Hasil penelitian menunjukkan adanya peningkatan warna resin komposit yang direndam dalam larutan karbonasi selanjutnya direndam dalam larutan cuka dari 0,72 menjadi 1,52 dan dalam jeruk nipis dari 0,68 menjadi 1,48 . Simpulan: Terdapat perubahan warna lebih cerah pada resin komposit yang direndam pada larutan cuka dan jeruk nipis.
\end{abstract}

Kata kunci: Resin komposit, perubahan warna, larutan cuka, jeruk nipis 
Pada era globalisasi masyarakat Indonesia terlebih khusus di Sulawesi Utara mulai sadar akan kesehatan gigi dan mulut. Kesadaran masyarakat tersebut tidak hanya mengenai penyakit gigi dan mulut, melainkan juga masalah estetik gigi. Estetik yang baik dapat dilakukan dengan banyak cara, salah satunya tindakan penumpatan. Bahan tumpatan yang biasa digunakan yaitu resin komposit. ${ }^{1}$

Resin komposit memiliki kelebihan dari segi estetik karena tersedia dalam berbagai pilihan/tipe warna yang mirip dengan warna dan struktur gigi. ${ }^{1}$ Umumnya resin komposit dapat bertahan selama 6-12 tahun jika dirawat dengan baik dan menghindari makanan atau minuman yang dapat menyebabkan perubahan warna. Resin komposit memiliki kecenderungan berubah warna (diskolorisasi) pada saat digunakan di rongga mulut. ${ }^{2}$

Mengonsumsi minuman berkarbonasi, minuman berwarna, dan merokok merupakan faktor yang menyebabkan terjadinya perubahan warna karena sifat fisik resin komposit mudah menyerap air dan cairan dalam mulut. ${ }^{3,4}$ Perubahan warna menjadi penyebab diperlukannya penggantian bahan tumpatan karena tidak estetik sehingga tidak menunjang penampilan seseorang. ${ }^{3}$ Alternatif lain yang dapat digunakan sekaligus menghemat biaya yaitu dengan cuka dan jeruk nipis yang dapat mengangkat zat-zat warna yang menempel pada komposit.

Cuka (asam asetat) merupakan bahan yang sering digunakan dalam kehidupan sehari-hari. ${ }^{5}$ Pada kandungan cuka terdapat asam karboksilat yang berkemampuan memutihkan gigi dengan mengoksidasi permukaan email sehingga menjadi netral dan menimbulkan efek pemutih gigi. ${ }^{6}$ Cuka digunakan sebagai pemberi rasa asam pada makanan dan sebagi pengawet. Selain murah cuka juga mudah diperoleh di pasaran. $^{7}$

Jeruk nipis merupakan salah satu buahbuahan yang mudah didapatkan dan sering digunakan untuk berbagai keperluan. Banyak manfaat dari buah ini dalam bidang kesehatan, diantaranya sebagai antibakteri, antifungal, antioksidan, antikanker, antikolesterol, dan sebagai pemutih gigi. ${ }^{8}$ Jeruk nipis berkhasiat memutihkan gigi, dan kandungan asam sitrat pada daging buah jeruk nipis memiliki $\mathrm{pH}$ yang hampir sama dengan $\mathrm{pH}$ pemutih gigi alami seperti stroberi asam. ${ }^{9}$

Penelitian ini bertujuan untuk mengetahui perubahan warna tumpatan resin komposit pada perendaman larutan cuka dan jeruk nipis.

\section{METODE PENELITIAN}

Jenis penelitian ini ialah eksperimental semu dengan pretest and posttest group design. Penelitian ini dilakukan di Laboratorium Kimia Fakultas MIPA Universitas Sam Ratulangi Manado pada bulan April-Mei 2018.

Sampel sebanyak 10 resin komposit berbentuk lingkaran dengan tebal $2 \mathrm{~mm}$ dan diameter $5 \mathrm{~mm}$ yang telah direndam dalam larutan karbonasi. Larutan yang disediakan ialah 1 botol asam cuka $100 \mathrm{ml}$. Larutan jeruk nipis dibuat dari 500 gram daging buah nipis dicuci dan dibelah menjadi empat bagian, dan disaring menggunakan saringan untuk memisahkan air dengan biji dan ampasnya. Hasil perasan jeruk nipis diambil takarannya sebanyak $40 \mathrm{ml}$ sedangkan larutan cuka diambil takaran yaitu $10 \mathrm{ml}$ cuka dan ditambahkan air $30 \mathrm{ml}$ sehingga volume larutan menjadi $40 \mathrm{ml}$. Pengukuran $\mathrm{pH}$ menggunakan $\mathrm{pH}$ indikator untuk melihat tingkat keasamannya.

Pada pengujian sampel, disiapkan 10 sampel yang dibagi dua kelompok untuk setiap perlakuan. Sebelumnya sampel direndam terlebih dahulu, diukur warna awal masing-masing sampel. Kelompok I direndam dalam larutan cuka hingga hari ke-5 sedangkan kelompok II direndam dalam larutan perasan jeruk nipis hingga hari ke-5.

Pengukuran perubahan warna pada sampel resin komposit tiap kelompok dilakukan setiap hari selama jangka waktu 5 hari dengan menggunakan spektrofotometer. Pengukuran dilakukan dengan menggunakan 2 panjang gelombang yaitu 
panjang gelombang $645 \mathrm{~nm}$ dan $663 \mathrm{~nm}$. Setelah hasil dari masing-masing panjang gelombang didapatkan kemudian hasil dari panjang gelombang $645 \mathrm{~nm}$ dikurangi hasil panjang gelombang $663 \mathrm{~nm}$, kemudian dikalikan dengan 100, selanjutnya hasil yang didapatkan dalam bentuk persentase.

\section{HASIL PENELITIAN}

Pada penelitian ini sampel dibagi dua kelompok perendaman yang sebelumnya sudah direndam dengan larutan karbonasi (Cola). Pada kelompok I rerata kecerahan komposit yaitu 0,72 dan pada kelompok II 0,68. Sampel kelompok I direndam dalam larutan cuka dan sampel kelompok II direndam dalam perasan jeruk nipis selama 5 hari. Pengamatan dilakukan setiap hari pada jam yang sama selama 5 hari. Hasil pengamatan mendapatkan perubahan warna resin kom-posit yang direndam larutan cuka dan jeruk nipis yang bermakna.

Hasil pengukuran menggunakan alat spektrofotometer Biochrome Libra S12 $\mathrm{UV} / \mathrm{V}$ is mendapatkan warna awal resin komposit yang direndam dalam karbonasi mengalami peningkatan dari 0,72 menjadi 1,52 setelah direndam dalam larutan cuka. Demikian pula resin komposit yang direndam dalam larutan karbonasi dan selanjutnya direndam dalam jeruk nipis juga mengalami peningkatan dari 0,68 menjadi 1,48. Hasil pengukuran warna resin komposit kedua kelompok perlakuan dapat dilihat pada Tabel 1.

Tabel 1. Perubahan warna kedua kelompok yang diamati pada jam yang sama setiap hari selama lima hari

\begin{tabular}{cccccccc}
\hline \multirow{2}{*}{ Kelompok } & \multirow{2}{*}{ Sampel } & \multicolumn{7}{c}{ Hari } \\
\cline { 3 - 7 } & 1 & 0 & 1 & 2 & 3 & 4 & 5 \\
\hline \multirow{2}{*}{ Kelompok I } & 2 & 0,9 & 1 & 1,3 & 1,4 & 1,5 & 1,7 \\
(Larutan cuka) & 3 & 0,7 & 0,8 & 0,9 & 1,2 & 1,3 & 1,6 \\
& 4 & 0,9 & 1 & 1,1 & 1,2 & 1,3 & 1,5 \\
Rerata & 5 & 0,5 & 0,6 & 0,7 & 0,9 & 1,2 & 1,4 \\
& & $\mathbf{0 , 7 2}$ & $\mathbf{0 , 8 2}$ & $\mathbf{0 , 0 9 4}$ & $\mathbf{1 , 0 6}$ & $\mathbf{1 , 3}$ & $\mathbf{1 , 5 2}$ \\
Kelompok II & 1 & 0,6 & 0,7 & 0,9 & 1,1 & 1,3 & 1,5 \\
(Perasan jeruk nipis) & 2 & 0,9 & 1,1 & 1,1 & 1,3 & 1,4 & 1,6 \\
& 3 & 0,6 & 0,8 & 0,9 & 1,1 & 1,2 & 1,4 \\
Rerata & 4 & 0,5 & 0,6 & 0,8 & 0,9 & 1 & 1,2 \\
& 5 & 0,8 & 0,9 & 0,9 & 1,0 & 1,3 & 1,7 \\
& & $\mathbf{0 , 6 8}$ & $\mathbf{0 , 8 2}$ & $\mathbf{0 , 9 2}$ & $\mathbf{1 , 0 4}$ & $\mathbf{1 , 2 2}$ & $\mathbf{1 , 4 8}$ \\
\hline
\end{tabular}

Berdasarkan hasil pengukuran, terlihat bahwa komposit berubah warna menjadi gelap setelah direndam dalam larutan karbonasi selama 10 hari dan kemudian berubah warna menjadi lebih cerah setelah direndam dalam larutan cuka dan jeruk nipis selama 5 hari. Pengukuran warna dilakukan setelah perendaman dalam larutan karbonasi selama 10 hari, dan perendaman dalam larutan cuka dan air perasan jeruk nipis selama 5 hari. Pengukuran perubahan warna dilakukan dengan menggunakan alat spektrofotometer.

\section{BAHASAN}

Penelitian ini diawali dengan perendaman resin komposit dalam larutan karbonasi selama 10 hari agar terjadi diskolorisasi. Kemudian kesepuluh sampel yang sudah mengalami diskolorisasi direndam masing-masing 5 sampel dalam larutan cuka dan 5 sampel dalam perasan jeruk nipis selama 5 hari.

Pada hasil perendaman, dapat dilihat bahwa resin komposit yang telah direndam dalam larutan karbonasi mengalami perubahan warna yang bermakna pada peren- 
daman larutan cuka dan perasan jeruk nipis selama 5 hari. Perubahan warna pada masing-masing sampel diukur dengan alat spektrofotometer. Hasil penelitian ini sejalan dengan penelitian yang dilakukan oleh Sibilang et al. $^{2}$ mengenai uji air perasan jeruk kesturi (Citrus microarpa Bunge.) terhadap perubahan warna resin komposit yang direndam dalam larutan kopi dan jeruk kesturi selama 5 hari.

Resin komposit merupakan bahan tumpatan yang banyak dipakai oleh dokter gigi karena keunggulan estetiknya yang menyerupai warna gigi walaupun selama pemakaiannya dapat mengalami perubahan warna. Diskolorisasi pada resin komposit merupakan masalah dalam upaya mempertahankan estetik bahan restorasi yang sewarna dengan gigi. Perubahan warna pada resin komposit dapat disebabkan oleh beberapa faktor, yaitu intrinsik dan ekstrinsik. Faktor intrinsik berasal dari bahan itu sendiri yaitu matriks resin atau pada celah penghubung matriks dan filler karena kandungan bahan pengisi dapat menyerap air, sedangkan faktor ekstrinsik berasal dari zat warna minuman atau makanan yang dikonsumsi. ${ }^{10,11}$ Penelitian ini menggunakan minuman berkarbonasi Cola yang dapat mengakibatkan perubahan warna pada resin komposit. Perubahan yang terjadi pada resin komposit disebabkan oleh adanya difusi cairan mulut yang bercampur karamel yang terbuat dari pemanasan gula atau glukosa yang disertai dengan adanya alkali atau asam mineral di dalam minuman Cola. ${ }^{12}$ Solusi terhadap perubahan warna resin komposit tersebut yaitu dengan melakukan penggantian tumpatan namun untuk menghemat biaya terdapat beberapa alternatif bahan yang dapat digunakan seperti asam cuka dan jeruk nipis yang dapat mengangkat zat-zat warna yang menempel pada resin komposit. Hal ini perlu dilakukan penelitian lebih lanjut.

Cuka atau asam asetat memiliki rumus kimia $\mathrm{C}_{2} \mathrm{H}_{4} \mathrm{O}_{2}$ atau $\mathrm{CH}_{3} \mathrm{COOH}$. Adanya perbedaan elektronegatif di antara $\mathrm{O}$ dan $\mathrm{H}^{+}$pada gugus $\mathrm{OH}^{-}$yang lebih besar dibandingkan $\mathrm{CO}^{-}$dan $\mathrm{OH}^{-}$pada gugus
$\mathrm{COOH}$ menyebabkan gugus $\mathrm{OH}^{-}$akan lebih mudah putus dan menghasilkan ion $\mathrm{H}^{+}$. Ion $\mathrm{H}^{+}$yang terbentuk kemudian berikatan dengan 3 molekul $\mathrm{C}$ tersier yang terdapat pada komposit sehingga menyebabkan perubahan warna. Ion $\mathrm{H}^{+}$juga dapat menyebabkan pemutusan ikatan antara rantai pada senyawa dimetakrilat. Semakin lama perendaman dalam cuka, maka semakin banyak ikatan polimer pada resin komposit terputus menyebabkan air mudah menyerap pada komposit. ${ }^{13}$ Hasil penelitian ini sejalan dengan penelitian yang dilakukan oleh Istibsyaroh ${ }^{14}$ dimana gugus $\mathrm{OH}^{-}$ akan mudah putus dan menghasilkan $\mathrm{H}^{+}$.

Jeruk nipis memiliki kandungan asam sitrat yang berfungsi mencerahkan warna resin komposit yang telah berubah warna setelah perendaman dengan menggunakan minuman berkarbonasi. Hasil penelitian ini menunjukkan bahwa terjadi perubahan warna resin komposit yang direndam pada larutan karbonasi lalu direndam dengan menggunakan jeruk nipis. Hal ini disebabkan karena asam sitrat memiliki rumus kimia $\mathrm{C}_{6} \mathrm{H}_{8} \mathrm{O}_{2}$, gugus $\mathrm{OH}$ dalam struktur kimianya yang mampu merusak molekulmolekul zat warna yang menempel pada komposit sehingga membuat komposit dapat berubah warna menjadi lebih cerah. ${ }^{9,15}$ Penelitian ini juga menunjukkan jeruk nipis mempunyai $\mathrm{pH}$ yang rendah yaitu 3, sama dengan $\mathrm{pH}$ buah stroberi yang berpotensi mencerahkan warna gigi dimana asam yang rendah dapat mengikis permukaan email. ${ }^{12}$

Hasil penelitian ini menunjukkan bahwa resin komposit yang direndam pada larutan cuka dan jeruk nipis menyebabkan perubahan warna dari warna yang gelap menjadi lebih cerah karena dalam larutan cuka, dan jeruk nipis terkandung asam yaitu pada cuka mengandung asam asetat dan pada jeruk nipis mengandung asam sitrat. Kedua asam ini memiliki gugus yang sama yaitu gugus $\mathrm{OH}$ yang mampu merusak molekul-molekul zat warna yaitu dengan mengoksidasi ikatan konjugasi tersebut sehingga warna menjadi netral dan terlihat lebih cerah.

Limitasi penelitian ini ialah ukuran 
sampel yang dibuat tidak sesuai yang diharapkan yang menyebabkan ukuran sampel yang tidak baku, sehingga dapat memengaruhi perhitungan rerata nilai kecerahan sampel yang diukur dengan menggunakan spektrofotometer.

\section{SIMPULAN}

Dari hasil penelitian ini dapat disimpulkan bahwa terdapat perubahan warna menjadi lebih cerah dari resin komposit yang direndam dalam larutan cuka dan jeruk nipis, yang sebelumnya telah direndam dalam larutan karbonasi.

\section{SARAN}

Perlu dilakukan penelitian lebih lanjut untuk mengetahui tingkat konsentrasi dan keasaman dari larutan cuka dan jeruk nipis yang efektif dan aman untuk digunakan.

Penelitian ini dapat dikembangkan dengan menggunakan variabel, metode, dan analisis data yang berbeda agar $g$ dapat digunakan sebagai acuan dan bahan pembelajaran.

\section{DAFTAR PUSTAKA}

1. Anusavice KJ. Phillips Buku Ajar Ilmu Kedokteran Gigi (10th ed). Alih bahasa: Budiman JA, Purwoko S. Jakarta: EGC; 2003; p. 227-46.

2. Sibilang AAGC, Wowor PM, Juliatri. Uji air perasan jeruk kesturi (Citrus micropa Bunge.) terhadap perubahan warna resin komposit yang direndam dalam larutan kopi. eG. 2017;5(1):13.

3. Effendi MC, Nugraeni Y, Pratiwi RW. Pengaruh lama perendaman terhadap perubahan warna resin komposit nanohibrida akibat konsumsi minuman soda Aneka Warna dan Rasa. p. 2. Available from: http://old.fk.ub.ac.id /artikel/id/filedownload/gigi/majalah\% 20rizky\%20widya\%20p.pdf

4. Kristanti Y. Perubahan warna resin komposit nanohibrida akibat perendaman dalam larutan kopi dengan kadar gula yang berbeda. Jurnal PDGI. 2016;65(1):27.

5. Bragg P. Khasiat Cuka (Cairan Ajaib Penyembuh Alami). Jakarta: Hikmah, 2008; p. 251-3.
6. Sutresna N. Cerdas Belajar Kimia (3rd ed). Jakarta: Grafindo Media Pratama, 2007; p. 229.

7. Nurika I, Hidayat N. Pembuatan asam asetat dari air kelapa secara fermentasi kontinyu menggunakan kolom biooksida (kajian dari tinggi partikel dalam kolom dan kecepatan aerasi). Jurnal Teknologi Pertanian. 2001;2(1):52.

8. Prastiwi SS, Ferdiansyah F. Kandungan dan aktivitas farmakologi jeruk nipis (Citrus aurontifolia s.). Farmaka. 2017; 15(2):1,2,6.

9. Nurbaetty R, Dwi MChR, Sri L. Potensi jeruk nipis (Citrus aurontifolia) dalam memutihkan email gigi yang mengalami diskolorasi. IDJ. 2014;3(1):79.

10. Widyastuti NH, Hermanegara NA. Perbedaan perubahan warna antara resin komposit konvensional, hibrid, dan nanofil setelah direndam dalam obat kumur Chlorhexidine Gluconate 0,2\%. JIKG. 2017;1(1):56.

11. Farahanny W. Perbedaan diskolorisasi restorasi resin komposit yang dipolis dan tidak dipolis pada perendaman larutan kopi hitam dan kopi krimer. Medan: Fakultas Kedokteran Gigi Universitas Sumatera Utara; 2009.

12. Dewi SRP, Bikarindrasari, Oktaviani W. Pengaruh berbagai minuman terhadap stabilitas warna pada resin komposit nanofil; p. 4. Available from: http: //docplayer.info/41702224-Pengaruhberbagai-minuman-terhadap-stabilitaswarna-pada-resin-komposit-nanofill. Html.

13. Asmawati, Aulia M. Pemanfaatan buah strawbery sebagai bahan pemutih gigi. Makasar Dent J. 2016;5 (2):40-3.

14. Istibsyaroh. Perubahan warna resin komposit nanofiller setelah perendaman dalam minuman susu fermentasi (Penelitian in vitro) [Skripsi]. Jember: Fakultas Kedokteran Gigi Universitas Jember; 2015.

15. Januarizqi K, Erlita E, Diana S. Perbandingan efektivitas jus buah nanas (Ananas comosus) dengan jus buah stroberi (Fragaria xannanasea) sebagai bahan alami pemutih gigi eksternal. Dentino. 2017;1(1):76-7. 